\title{
Experimental Study for Soil Modification Cement Grouting
}

\author{
Majid Ahmadpour ${ }^{1}$ \\ 1 University of Mazandaran, Babolsar, Iran, e-mail: mj.ahmadpour@umz.ac.ir
}

\begin{abstract}
Soil modification with Portland cement is the most common practice in geotechnical engineering. The application of micro-fine cement causes proper intrusion of the provided slurry into the soil voids and consequently decreases the porosity to a greater quantity. In order to determine the utility and behavior of cements with different blains, non-destructive and destructive tests such as grain-size distribution of cements by laser-ray, sedimentation, permeability and compressive strength were employed. The results of experimental studies and observations demonstrated a suitable mix-design for upper and lower parts of the cement-grading curve that are of prime importance for grouting and stabilization. Meanwhile, by increasing the fineness of the cement, the permeability decreases to a considerable extent and the compressive strength increases. Moreover, the blain content close to $5000 \mathrm{~cm}^{2} / \mathrm{gr}$ application led to the optimization of the effect of void reduction in a grouted soil mass compared to the lower and higher amount of blain content. The results of various tests indicate that an optimum blain can be used to achieve the designed geotechnical criteria.
\end{abstract}

Keywords: experimental study, soil modification, micro fine cement, grouting

\section{INTRODUCTION}

Distribution of problematic soils, i.e. those with high moisture and low efficiency poses many difficulties to construction projects. All improvement techniques seek an increase in density and shear strength, providing stable condition, as well as reduction of soil compressibility and control ground water flow, or increasing the rate of consolidation $[5,6,15]$. Classification of ground modification techniques includes five major categories:

1) Earthworks.

2) Densification.

3) Physical and chemical modification.

4) Hydraulic modification.

5) Reinforcement.

Portland cement is one of the most common materials used in soil improvement and grouting industry. In some cases, where the existing voids in the soil are very small, using coarse-grained cement for grouting is practically impossible. One practical approach to overcome this difficulty is utilizing micro-fine cement. Micro-fine cement particles are very tiny, ground more than ordinary cements and their specific area is relatively high. In this paper, non-destructive and destructive tests were employed to investigate micro-fine cement behavior with different blains and for this purpose experimental studies were performed in the Abiek Cement Production Complex in Iran. The outcome of the experiments will lead to the production of cement with suitable blain for projects requiring grouting such as constructing a base and/or cover liner located on pervious geomaterials to reduce the infiltration into and leaching out of the site $[1,7,9]$.

\section{EXPERIMENTAL STUDIES}

In order to evaluate the slurry function made of micro fine cement, the samples were created by compacting the soil in three layers, each layer by 10 blows into ready-made moulds. Then, the slurry was injected into the soil mass through the spaced array of vertical perforated pipes driven into the samples $[2,3,4]$. 
The main systematic procedure for the present research work involves the following:

- Particular attention was given to two soil types investigated, which are in the form of finegrained sands. They are situated near Tehran City, and used for making concrete. A detailed study of both soil particles encountered was performed by means of sieve analyses. Grading of these soils is presented in Figure 1. The grading curve in Figure 1A shows a finegrained but poorly graded soil. The grading curve in Figure 1B shows it to be predominantly more fine-grained but well-graded soil. Geologically speaking, these soils are typical of fine-grained alluvium which are deposited in south of Tehran plain.

- In order to perform the grouting, two series of cylinder-shaped moulds were made of 155 $\mathrm{mm}$ diameter and of 180 and $240 \mathrm{~mm}$ height. For experimental studies, $360 \mathrm{~kg}$ cement of ordinary type 1 with different blains was used.

- Four sets of samples were prepared; the first set included 12 compacted samples of soil type 1 grouted with blain cement of 3000 , $3900,4600,5100,6000,6800$ and $7000 \mathrm{~cm}^{2} /$ gr. A limited amount of 200, 300 and 500 gr slurry was injected into the soil mass. The second and third sets included 26 compacted samples of soil type 2 , which were grouted with the same blain cements until the refusal of slurry cement took place. These samples were prepared at two water/cement ratio of 1.5 and 1.8. The fourth set included 10 mortar samples of soil 2, which were prepared with the compaction method in which the soil samples were premixed and compacted with 5 blows in moulds with the same blain cement as mentioned before at two water/cement ratios of 0.7 and 0.9 .
- Unexpected results from the permeability and sedimentation tests and uncertainties about the fineness of the consumed cements led to the use of specialized Laser-ray technique by in order to determine the grading and fineness of cement particles. The grading curves of all blain cements were determined accurately In Abiek Research and Development Center of Cement Plant. The device output determined the accumulating curves of percentage of passing and remaining of particles with a range of particle size between 0.5 to 1000 microns.

- Sedimentation tests carried out on the slurry made of cement with different blains. In order to decrease the amount of sedimentation, stabilizing material was used for less than 10 percent. The most common material for stabilizing the water-cement mixture is bentonite. cement was used in the amount of 1 to $4 \%$ by weight for the stabilization and desedimentation of slurry. It was found that the sedimentation decreased from $20 \%$ to 10 and $5 \%$, respectively. A $500 \mathrm{cc}$ cylinder with $10 \mathrm{~mm}$ diameter was used for the sedimentation tests. The amount of sedimentation was measured by centimeter at different intervals and the quotient resulting from the division of this number by the total height of the slurry was calculated in percentage.

- The falling-head permeability test was performed on the grouted samples. This method was considered to assess a particularly important aspect of physical and mechanical properties of grouted samples without any disturbance. The test condition simulates the field circumstances [17].

- The uniaxial compressive strength of third and forth sets of remolded samples was measured after 28 days.

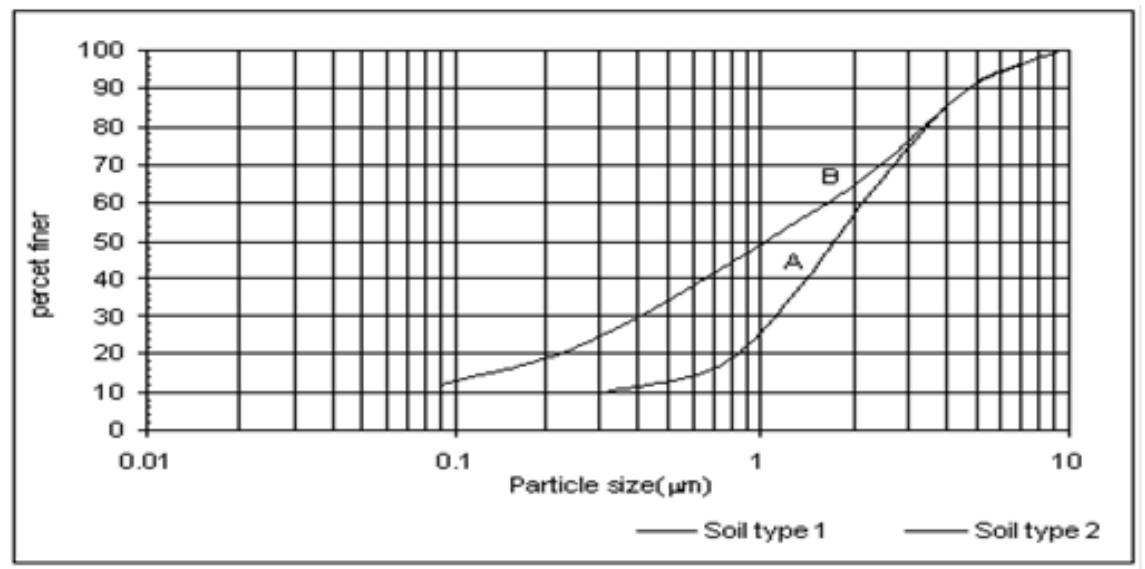

Fig. 1. Grain size distribution curves of two soil samples 


\section{RESULTS AND DISCUSSIONS}

\section{Cement grading curve by the laser-ray}

Generally, fine-grained soils cannot be treated effectively using the normal cement slurry. This is because it contains particles up to $40 \mathrm{~mm}$, which may block off fine pores in the soil, thus grouting with the slurry made of normal cement, the solid particles would be deposited before reaching the specified location in soil voids and a smaller grouting area would be formed $[12,13]$.

For this reason, the blain cement was scanned by laser-ray in order to determine the grading curve. Thirteen cement samples with different blains were analysed with the laser device. The selected grain size distribution curves, Figures 2 and 3 are related to the blain cement content of 3000 and $7000 \mathrm{~cm}^{2} / \mathrm{gr}$ and in Figure 4, all of the used gradation curves were compared with each other. Regarding the low percentage of passing 4 $\mathrm{mm}$, there is not much difference in the size of the cement particles in various blains, while in high percentage passing ( $80 \%$ to $100 \%$ ), the size of the particles of blain 7000 is much larger than for a cement with other blains. It is possible that a part of coarse-grains is the cause of enhanced hydration of fine-grains compared with that expected from the grinding of coarse-grains.

\section{Sedimentation tests}

In order to achieve the workability of slurry, the sedimentation test was performed on the samples with blain cement of $3000,3900,4600$, $5100,6000,6800$ and $7000 \mathrm{~cm}^{2} / \mathrm{gr}$. The blain cement of $5100 \mathrm{~cm}^{2} / \mathrm{gr}$ showed the lowest amount of sedimentation at any elapsed time among the other blain cements. By increasing the fineness of cement, the amount of sedimentation increases sharply with time. Then, after $90 \mathrm{~min}$, the rate of sedimentation ceased, as shown in Figure 5. The sedimentation can be directly related to the cement-bleeding rate. The more sedimentation of a selected cement type, the higher the cementbleeding rate.

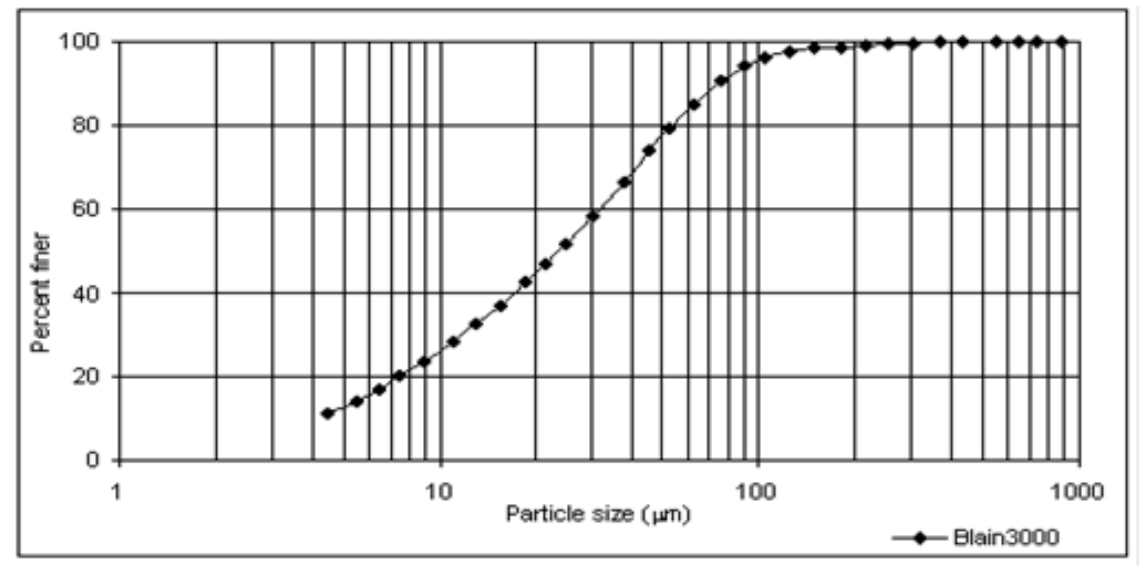

Fig. 2. Grain size distribution by laser-ray for blain cement $0 \mathrm{f} 3000 \mathrm{~cm}^{2} / \mathrm{gr}$

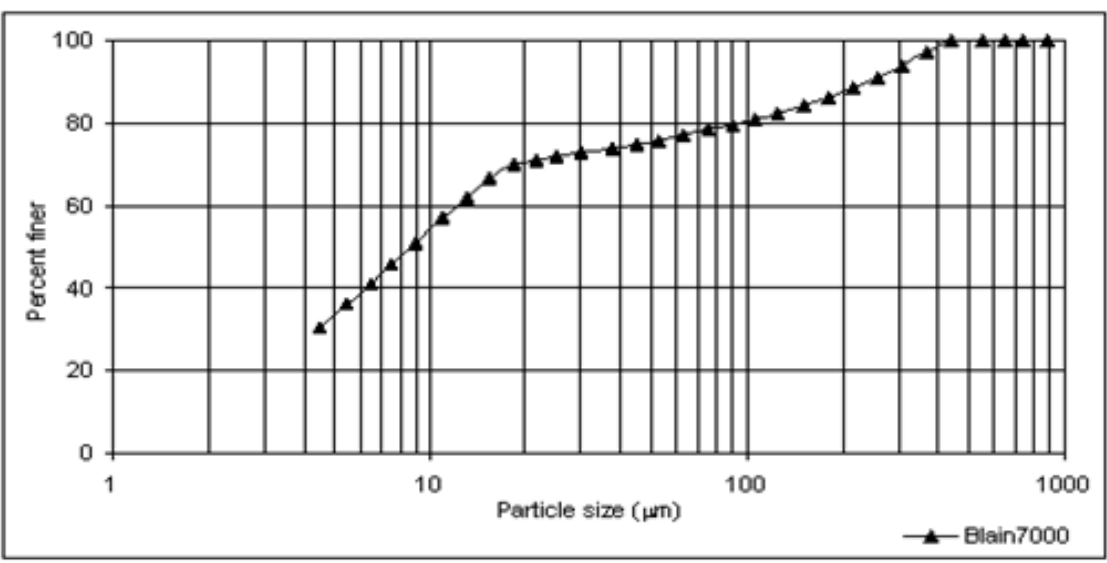

Fig. 3. Grain size distribution by laser-ray for blain cement $0 \mathrm{f} 7000 \mathrm{~cm}^{2} / \mathrm{gr}$ 


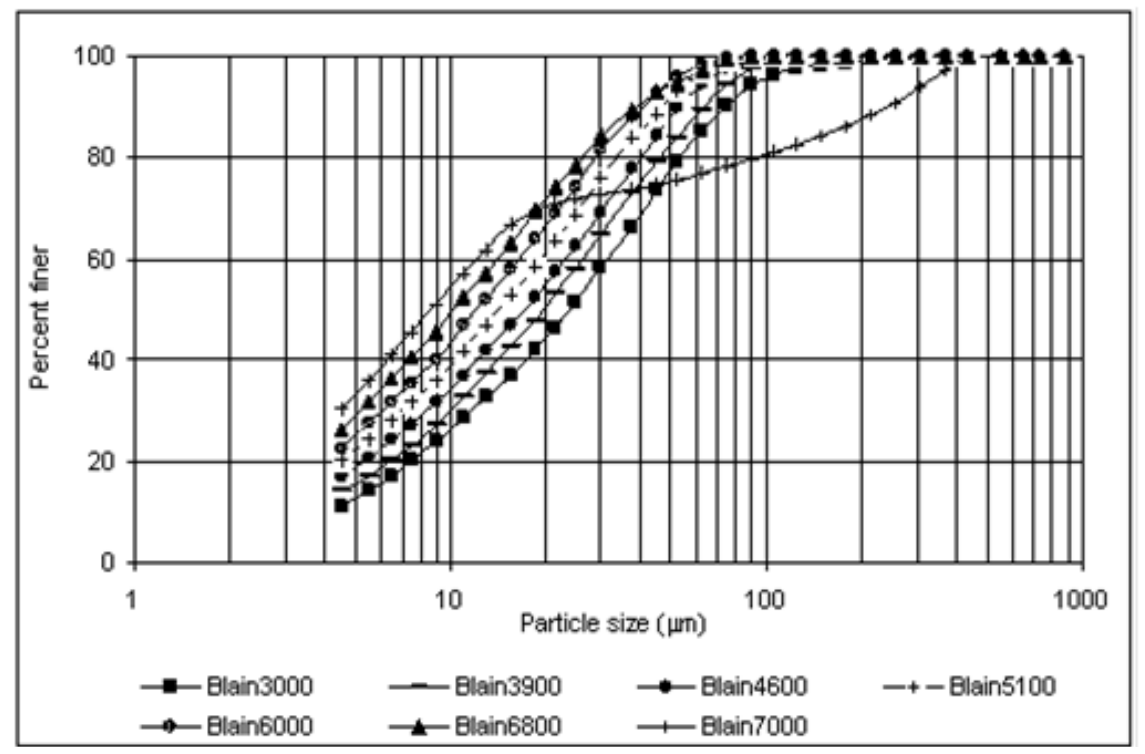

Fig. 4. Comparison of grain size distribution of all of the 7 blain cement

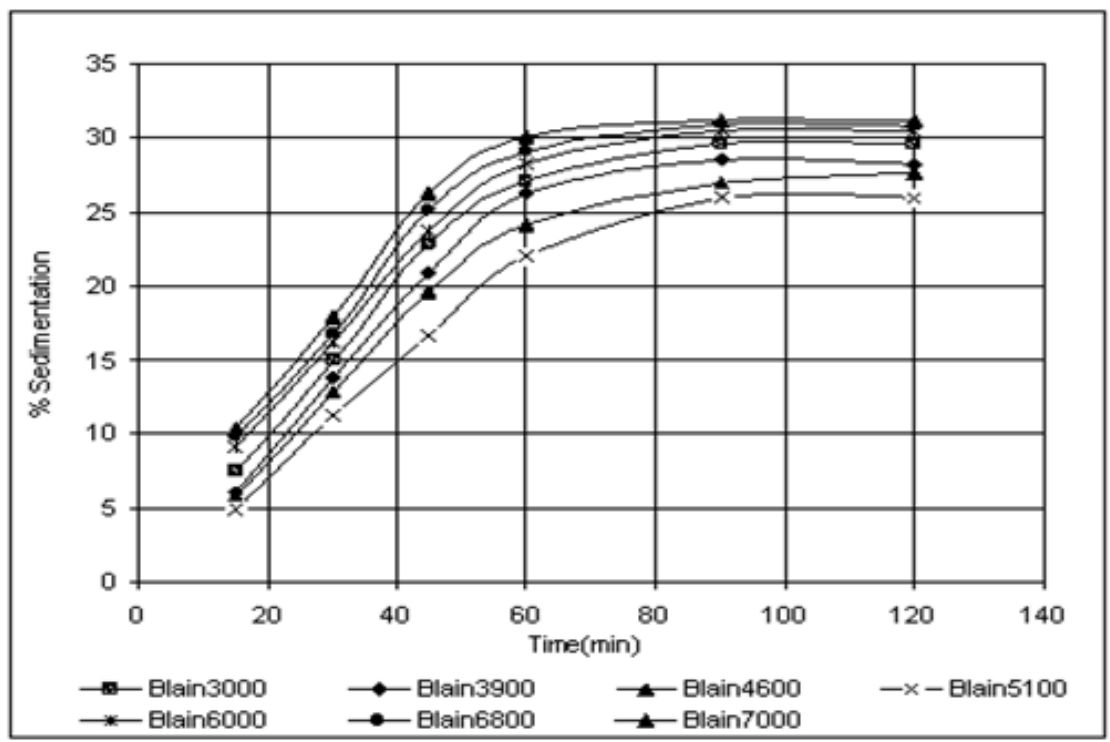

Fig. 5. The effects of blain cement on sedimentation quantity of slurry versus time

\section{Permeability tests}

In this study, three sets of samples were tested after two weeks of grouting. The first set of samples was provided with a limited amount of blain cement of 200, 300 and 500 grams. As a consequence, $\mathrm{F}=10 \%, 15 \%, 25 \%$ of the pores were filled with slurry, respectively. The slurries made of blain cement content of 5100 and 6000 $\mathrm{cm}^{2} / \mathrm{gr}$ had the best grouting efficiency and the lowest permeability as shown in Figure 6. In all volumes of slurry, by increasing fineness of blain cement from 3000 to $5100 \mathrm{~cm}^{2} / \mathrm{gr}$, permeability decreased about one-fourth. However, by increasing the fineness between 5100 to $6000 \mathrm{~cm}^{2} / \mathrm{gr}$ permeability did not change drastically for the grout- ing slurry content of 200 and 300 grams, but for the grouting slurry of 500 gram, permeability was increased up to twice. Afterwards, by increasing fineness between 6000 to $7000 \mathrm{~cm}^{2} / \mathrm{gr}$, the permeability increased about twice to three times.

As with permeation grouting, except for the absence of an idealized theory, predetermined volumes of grout based on estimates of the volume of voids to be treated were injected in the soil through the perforated pipes. Therefore, the volume of the grout can be calculated by Eq. 1 .

$$
\mathrm{V}_{\mathrm{g}}=\mathrm{V}_{\mathrm{z}}(\mathrm{n} \times \mathrm{F})(1+\mathrm{L})
$$

where: $\mathrm{V}_{\mathrm{g}}$ - volume of grout, $\mathrm{V}_{\mathrm{z}}^{\mathrm{g}}-$ volume of grouted soil, 


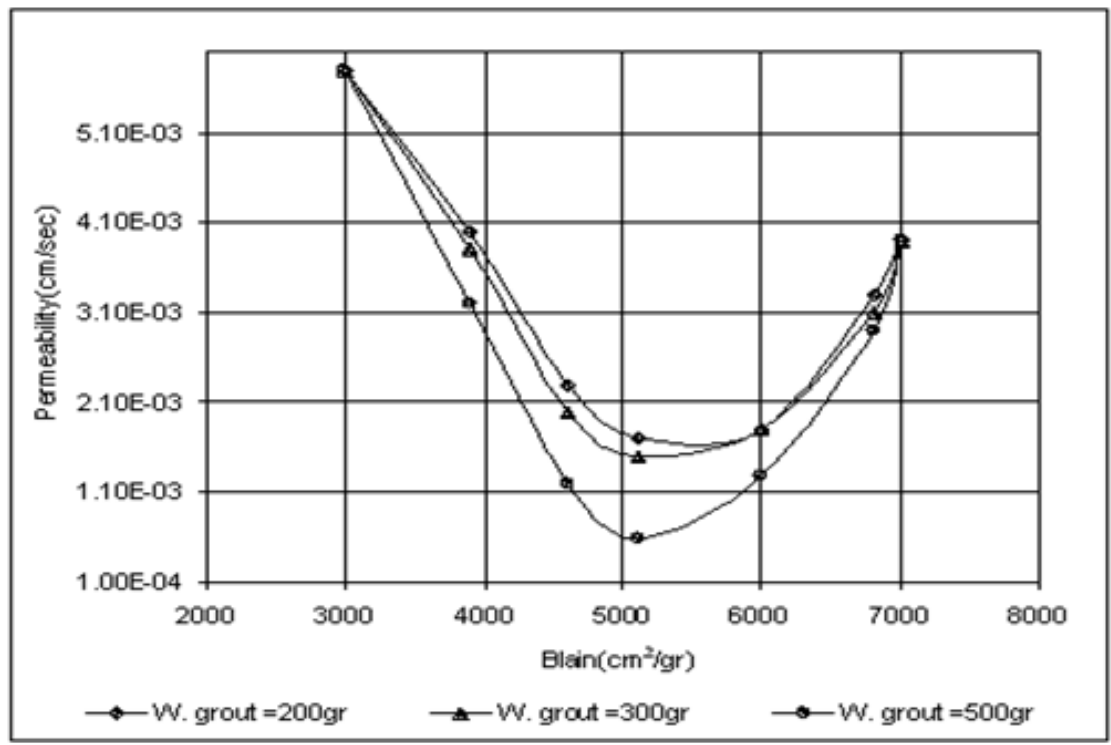

Fig. 6. The effects of weight of grout on permeability versus blain cement

$\mathrm{n}$ - soil porosity,

$\mathrm{F}$ - coefficient of filling voids,

$\mathrm{L}$ - coefficient.

In the second set of samples, the volume of the grouting slurry was not limited; it implies that grouting was continued until slurry refusal took place on the surface of the samples. As a consequence, $\mathrm{F}=45 \%$ of the soil voids were filled with slurry. In these tests, the permeability of the samples was lower than in the first set, even for different blain cement (Fig. 7). Regarding the slurry of blain cement of $5100 \mathrm{~cm}^{2} / \mathrm{gr}$ as well as the homogeneous and radial spreading of the grout into the soil, it can be concluded that the slurry reached the top of the sample quickly and consequently, penetration became clogged. The weight of the sample is rather low (Fig. 8), but its permeability was decreased to a considerable extent and was less than for other grouted samples. Although the weight of the sample grouted with blain cement of $7000 \mathrm{~cm}^{2} / \mathrm{gr}$ was the highest among the samples (Fig. 8), its permeability was not the lowest.

In the third set of samples with different water/cement ratio, as shown in Figure 9, the slurry made of blain cement $5100 \mathrm{~cm}^{2} / g r$ caused the greatest decreasing of the grouted soil permeability, and the only little difference is related to different water/cement ratios.

In these samples, by increasing the number of vertical perforated pipes in the samples, a greater quantity of slurry was injected, filling up $60 \%$ of the fine pores of soil with the same pressure insuf- ficient to disturb the soil structure, as applied in the second set of samples. Thus, the permeability of the samples was decreased (Fig. 10). From the results of the experiments in the second and third sets of samples it can be concluded that despite the increase in the weight of the samples (Fig. 8 ), the permeability was not decreased with the same rate like the second set. The reason is that the slurry made of blain cement content of 5100 $\mathrm{cm}^{2} / \mathrm{gr}$ dispersed steadily, displacing air and water outwards in a radial path homogeneously but the blain cement of $7000 \mathrm{~cm}^{2} / \mathrm{gr}$ did not.

In uniform soils, spherical flow was observed and assuming Darcy's law and a Newtonian fluid, Raffle and Greenwood [16] show that the flow rate $\mathrm{Q}$ at a radius of penetration $\mathrm{R}$ is related to the hydraulic driving head $\mathrm{H}$ given by Eq. 2 .

$$
\mathrm{H}=\frac{\mathrm{Q}}{4 \pi \mathrm{k}}\left[\mu\left(\frac{1}{\mathrm{r}}+\frac{1}{\mathrm{R}}\right)+\frac{1}{\mathrm{R}}\right]
$$

where: $\mathrm{k}$ - soil permeability,

$\mathrm{m}$ - grout viscosity in centipoises,

$\mathrm{R}$ - radius of spherical injection source.

The time for the grout to penetrate to radius $\mathrm{R}$ is given by Eq. 3 .

$$
\mathrm{t}=\frac{\mathrm{nr}^{2}}{\mathrm{kH}}\left[\frac{\mu}{3}\left(\frac{\mathrm{R}^{3}}{\mathrm{r}^{3}}-1\right)-\frac{\mu-1}{2}\left(\frac{\mathrm{R}^{2}}{\mathrm{r}^{2}}-1\right)\right]
$$

If the second component inside the main bracket is ignored, the relationship simplifies the equation proposed by Maag [14]. 


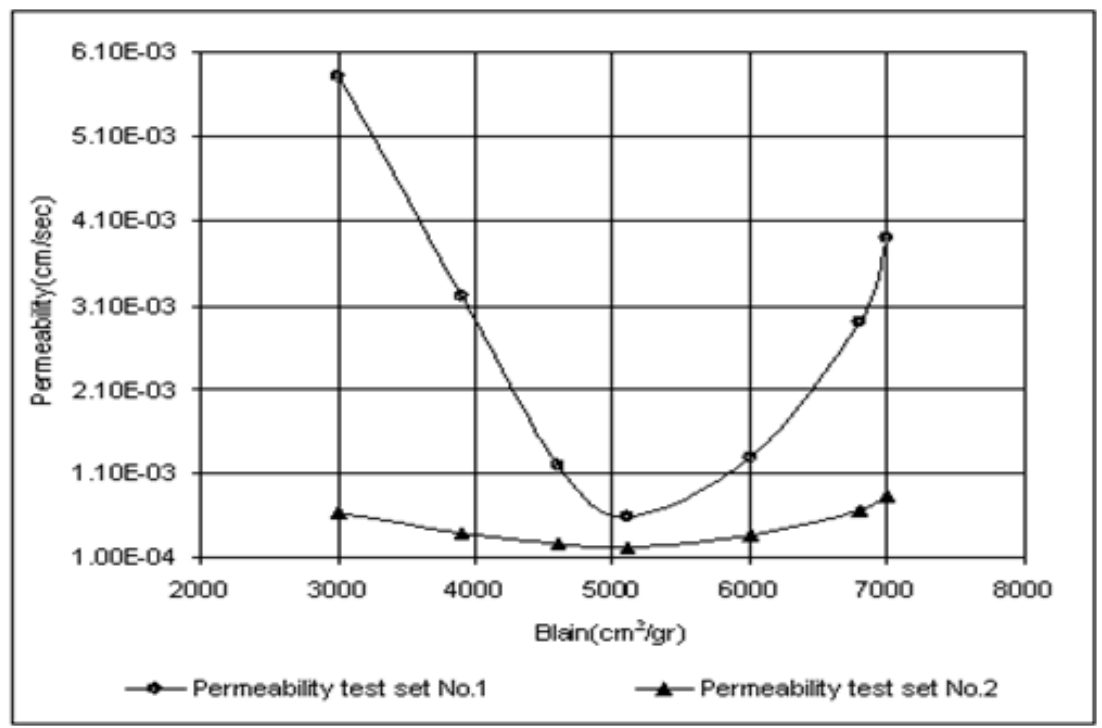

Fig. 7. Comparison of permeability of the $1^{\text {th }}$ and $2^{\text {nd }}$ sets of samples with different blain cement

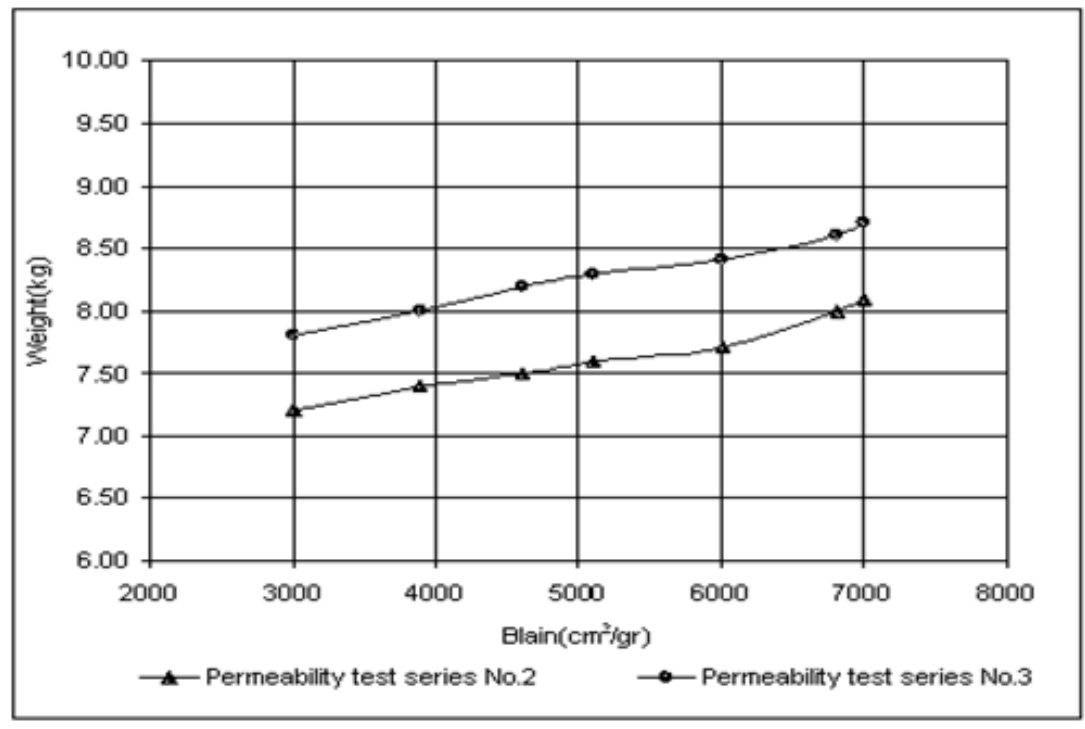

Fig. 8. Comparison of the weight of the grouted samples versus blain cement for two sets of samples 1 and 2

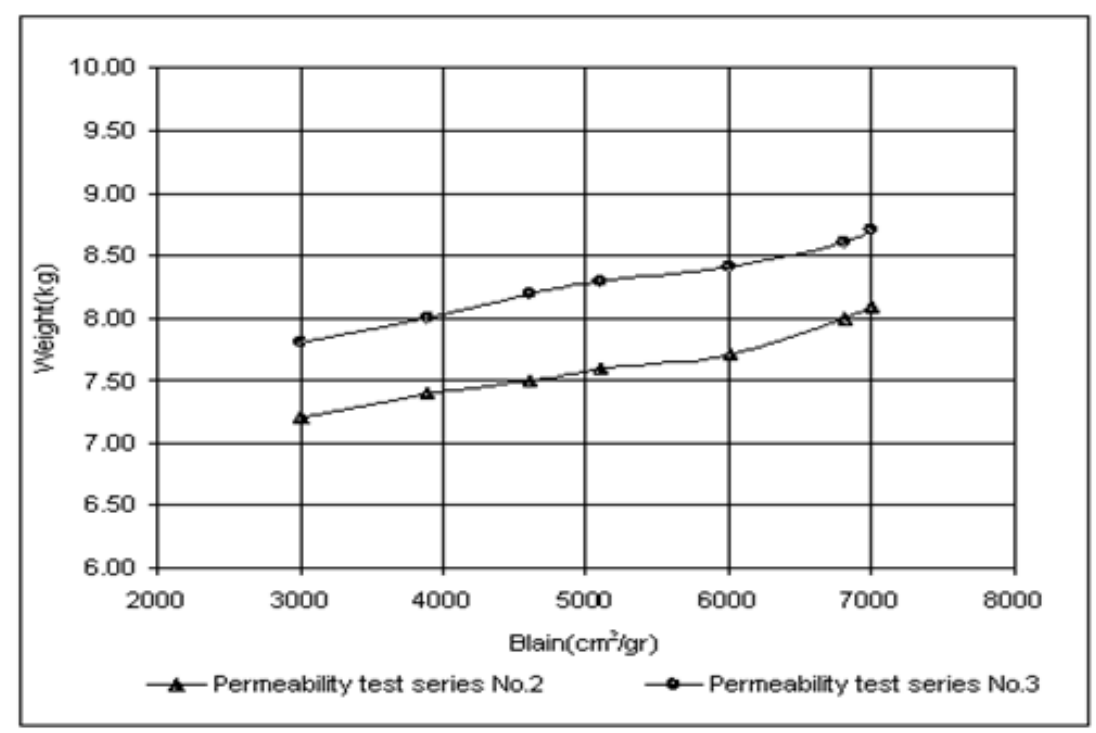

Fig. 9. The effects of water/cement ratio on permeability versus blain cement 


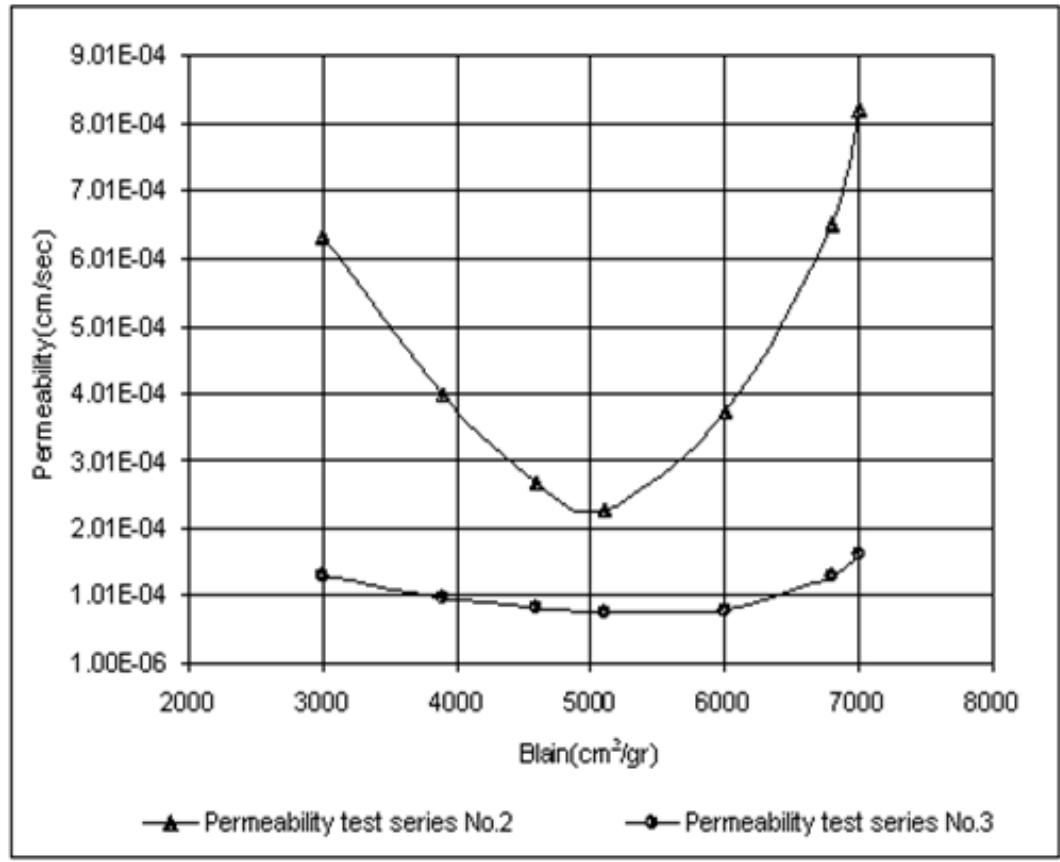

Fig. 10. Comparison of permeability versus blain cement for the second and third sets of samples

\section{Compressive strength tests}

In this sequence of experiments, when the third set of samples was taken out of the moulds, after 7 days, it was observed that only the samples grouted with the blain cement content of 5100 and $6000 \mathrm{~cm}^{2} / \mathrm{gr}$ had sufficient integrity and were formed in the shape of a perfect cylinder. Therefore, it was only possible to determine the compressive strength of these samples. The compressive strength of the sample grouted by the blain cement content of $5100 \mathrm{~cm}^{2} / \mathrm{gr}$ was greater than in other samples, as shown in Figure 11.
This complied with the results obtained from the permeability tests on the samples of the first and second sets. It can be concluded that - generally - by reduction in permeability, the compressive strength of the soil enhances because of the more cohesion and bonding of the soil particles resulting the increase in shear strength of the soil.

On 10 samples of mortar made of four types of former blain cement at two different water/cement ratios, the axial loading test was performed after 28 days. The present tests showed that the effect of ageing, even over relatively short periods, was to move the state inside the state boundary

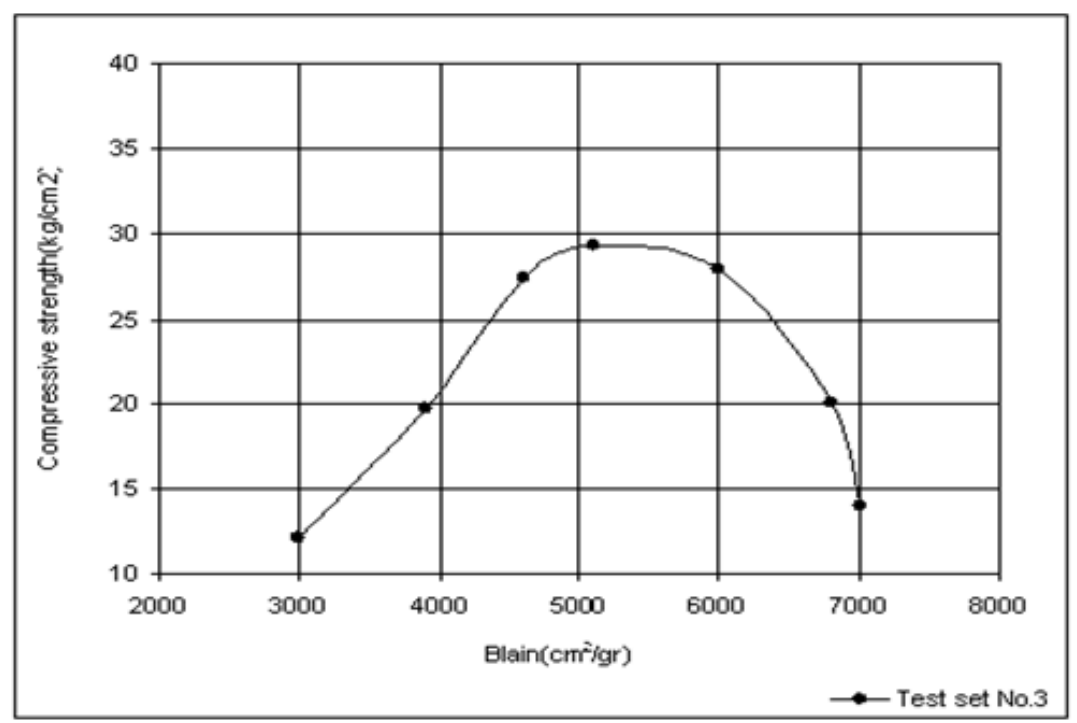

Fig. 11. Compressive strength versus blain cement of the third set of samples 


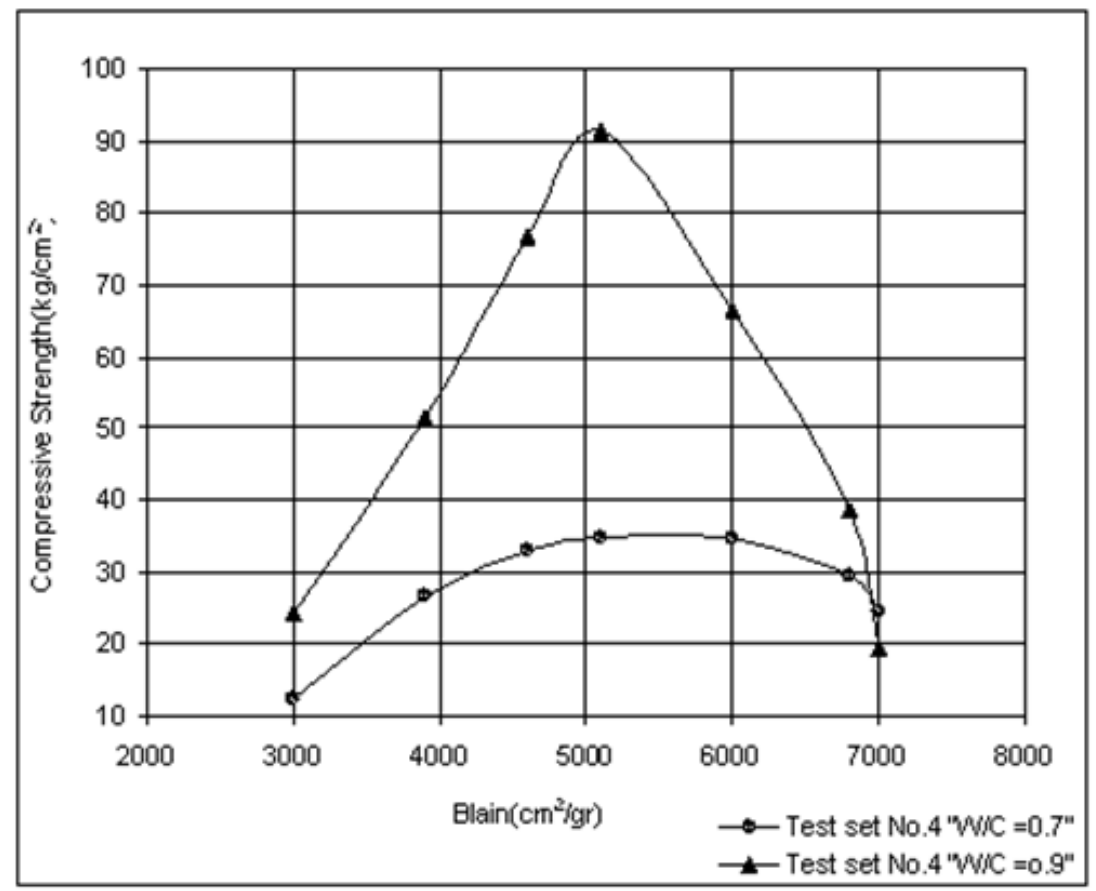

Fig. 12. The effects of water/cement ratio on compressive strength versus blain cement for mortar samples

surface. This also demonstrates that the homogeneous dispersion of slurry, with the blain cement content of $5100 \mathrm{~cm}^{2} / \mathrm{gr}$, in a cohesionless soil had the effect of increasing cohesion and bonding over a period of time whilst the angle of internal friction remains sensibly the same. Therefore, the samples can achieve greater strength as illustrated in Figure 12. It can also be observed that by increasing the water to cement ratio, the compressive strength was improved (Fig. 12).

\section{CONCLUSIONS}

Among the variation techniques for soil treatment, grouting and soil cement mixture, realized as a physical and chemical modification approach, the behavior of micro-fine cement with different blains was studied. Two types of soils tested were compacted, which was intended to show their fundamental physical and mechanical behavior after grouting. The conclusions drawn from this study are limited to the study of permeability and compressive strength changes without considering the ageing effect.

Grouting by slurry of blain cement was used for assessing the performance of a safe and stabilized geomaterials. Using blain cement with various tiny particles, which are the ground of ordinary cement, was the main object of this research. Preparation of the cement blain using the method of air penetration solely cannot be useful for evaluating the cement content for grouting purposes. In order to gain an accurate particle size of the cement, the Laser-ray method was implemented as a reliable device. The information obtained from Laser-ray was used to find that the coarse-grained part of the grain-size distribution curve is important. The most satisfactory results were derived when lesser amount of coarse-grains existed in blain cement. Coarse-grains are sometimes present in blain cement due to the hydration phenomena that can be avoided. Therefore, for a proper mix-design, the upper part (coarse-grained) and the lower part (fine-grained) of the grading curve are of prime importance for grouting and stabilization that can be taken into consideration.

The main use for the permeability information thus obtained is the assessment of how the grouting was advanced steadily in the soil voids. Since the addition of water/cement ratio causes the increase of permeability; therefore, the viscosity of slurry was controlled by the addition of bentonite clay. The results of permeability tests showed that the samples grouted by the blain cements of 3000 and $7000 \mathrm{~cm}^{2} / \mathrm{gr}$ in different volumes have almost the same permeability. In contrast, the samples grouted by blain cement of $5100 \mathrm{~cm}^{2} / \mathrm{gr}$ possessed the least permeability, being less permeable for blain cement of $6000 \mathrm{~cm}^{2} / \mathrm{gr}$, as a result of increased volume of slurry. 
On the basis of a simple view of permeability results, it was anticipated that the presence of inter-particle bonding will increase the stiffness, as well as the compressive strength of the samples. Thus, the samples of the third set, which were grouted with unlimited amount of slurry, having more perforated pipes, achieved higher compressive strength. In addition, the bonding between slurry and solid surface resists internal shirinkage stresses and thereby reduces the grout volume change. Therefore, the grouts that may not be suitable for the gravels and coarse sands may be entirely appropriate for the fine sands.

\section{REFERENCES}

1. Aflaki E., Sedighi P., Eslami A. Study on the failure behavior of three different stabilized problematic soils. Scientia Iranica Transaction A, Civil Engineering, 21(4), 2014, 1231.

2. Arenzana L., Krizek R..J, Pepper S.F. Injection of dilute microfine cement suspensions into fine sands. In: Proceedings of the 12th International Conference on Soil Mechanics and Foundation Engineering 1989. Publ by AA Balkema.

3. Arenzana L.M., An experimental investigation of the properties of dilute micro fine cement grouts, Northwestern University, USA, 1987, 172.

4. Becker D.E., Moore I.D. Canadian foundation engineering manual. CFEM, Bitech Publishers Ltd. British Columbia, 2006.

5. Bell F.G. Engineering treatment of soils. CRC Press, Apr 2014.

6. Burland J., Chapman T., Skinner H.D., Brown M. ICE Manual of Geotechnical Engineering. Vol. 2: Geotechnical Design, Construction and Verification. Feb, 2012.
7. Coumoulos D.G., Koryalos I.P. Grout mixtures for ground improvement-laboratory testing and quality control. In: Proceedings of the VIII European Conference of Soil Mechanics and Foundation Engineering, May 1983, pp. 23-26.

8. Elias V., Welsh J., Warren J., Lukas R. Ground improvement technical summaries. FHWA Publication No. FHWA-SA-98-086R. 2001; 2.

9. Eslami A., Performance of Stabilized and Improved Ground against Earthquake, The sixth Annual Conference on Studying the Analytic and Experimental Behavior of Structures under Dynamic and Earthquake loads, Rasht, Iran, 2000, 1-21.

10. Glendinning S., Jones C.J., Lamont Black J. Ground Improvement: Case Histories, Elsevier Geo-Engineering Book Series, 2005.

11. Hausmann M.R. Engineering principles of ground modification. New York: McGraw-Hill; 1990, pp. 632.

12. Houlsby A.C. Construction and design of cement grouting: a guide to grouting in rock foundations. John Wiley \& Sons; 1990, May 14.

13. Kutzner C. Earth and Rockfill Dams: Principles for Design and Construction. CRC Press; 1997.

14. Maag E. Ueber die Verfestigung und Dichtung des Baugrundes (Injektionen). Course on soil mech., Zurich Tech. School. 1938.

15. Moseley M.P., Kirsch K. Ground improvement. CRC Press; 2004, May 30.

16. Raffle J.F., Greenwood D.A. The relation between the rheological characteristics of grouts and their capacity to permeate soil. In: Proceedings of the $5^{\text {th }}$ International Conference of Soil Mechanics and Foundation Engineering, Paris, Jul 1961, Vol. 2, pp. 789.

17. Schwarz L.G., Krizek R.J. Effect of preparation technique on permeability and strength of cementgrouted sand. Geotechnical Testing Journal. 17(4), 1994, 434-443. 